\title{
“LEMBRA AQUELE DIA QUE A MILÍCIA PASSOU \\ POR AQUI?": TRAFICANTES, MILICIANOS E SUAS REPRESENTAÇÕES CONTRASTIVAS NA VIOLÊNCIA URBANA CARIOCA
}

\author{
Wellington da Silva Conceição*
}

\begin{abstract}
Resumo: Este texto traz uma análise sobre representações contrastivas presentes na violência urbana carioca em torno dos grupos conhecidos como "tráfico" e "milícia", tendo como corpus as memórias e reflexões de moradores da Cidade Alta (Rio de Janeiro) ativadas em torno de um episódio singular: a "tomada" deste espaço popular por um grupo armado conhecido como "milícia" e a "retomada" em menos de dois dias pelos traficantes que já atuavam no local.
\end{abstract}

Palavras-chave: Traficantes; milícia; representações.

Do you remember the day that the milicia stopped by?": Smugglers, militiamen and their contrastive representations in urban violence in Rio de Janeiro

Abstract: This text provides an analysis of opposites representations present in urban violence in Rio de Janeiro between the "drug dealers" and "militia", having the corpus memories and reflections of residents of the Cidade Alta (Rio de Janeiro) activated in a singular episode: the takeover of this popular space by an armed group known as "militia" and the "reconquest" in less than two days by the drug dealers who dominated the site.

Keywords: Drug dealers; militia; representations.

* Bacharel em Filosofia e Ciências Sociais; Mestre em Educação, Cultura e Comunicação em Periferias Urbanas (FEBF-UERJ); Doutorando em Ciências Sociais (PPCIS-UERJ). Pesquisador Associado do Laboratório de Etnografia Metropolitano/ LeMetro (IFCS-UFRJ ).

Recebido em: 30/08/2013 - Aceito em: 08/05/2014. 
“Recuerde-te el día que la milicia estuvo acá?": Contrabandistas, milicianos y sus representaciones contrastantes violencia urbana en Río de Janeiro

Resumen: Este texto propone un análisis de las representaciones contrastantes en la violencia urbana en Río de Janeiro en torno a los grupos conocidos como "tráfico" y "milicia" tomando como corpus de análisis los recuerdos y las reflexiones de los residentes de la Ciudad Alta (Río de Janeiro) acerca de un episodio singular: la "tomada" de este espacio popular por un grupo armado conocido como "milicia" y su "nueva tomada" en menos de dos días por los traficantes que ya estaban trabajando en el lugar.

Palabras clave: Traficantes, milicia, Representaciones.

\section{Introdução}

Quando analisamos a violência urbana (MACHADO DA SILVA, 2004) presente nas periferias da cidade do Rio de Janeiro, destacam-se dois distintos atores sociais, reconhecidos normalmente (pelo Estado e por boa parte da população) como criminosos: trata-se de grupos armados comumente chamados de tráfico e milícia ${ }^{1}$. São grupos que marcam a organização social e política nesta cidade por sua presença armada ostensiva em favelas e outras formas de habitação popular no Rio de Janeiro, gerando efeitos significativos para a sociabilidade local e a relação dos seus moradores com as demais formas de habitar a cidade. Mas

1 Sobre as categorias em destaque: ambas são categorias nativas, de uso na cidade do Rio de Janeiro. Tráfico serve para designar os grupos que têm como principal atividade a comercialização de drogas consideradas ilícitas pela lei brasileira, como maconha, crack e cocaína. Os agentes desse comércio são conhecidos como traficantes. Milícia identifica os grupos que na maioria das vezes se apresentam como agentes de segurança comunitária, formados principalmente por ex-militares. Geralmente mantêm sua atividade cobrando uma taxa aos moradores e comerciantes e não comercializam drogas. Seus agentes são conhecidos como milicianos ou milicos. Optei por utilizar as categorias nativas na hora de nomear/apresentar tais grupos no decorrer do texto. Outras especificações sobre esses grupos apresentarei no decorrer do texto. 
quando se confrontam os discursos sobre esses grupos, geralmente se destacam as suas diferenças, e não as semelhanças. A milícia, por exemplo, afirma sua legitimidade enquanto radicalmente diferente do tráfico. Tais instituições se apresentam no imaginário da violência urbana carioca a partir de representações que, a princípio, parecem opostas e não conciliáveis.

O objetivo deste artigo é trabalhar com essas representações contrastivas, que se manifestaram de forma privilegiada a partir de um evento particular, que foi a "tomada" (em 2 de fevereiro de 2007) da Cidade Alta (um sub-bairro de Cordovil - Rio de Janeiro) pelos milicianos e a "retomada"2 em menos de dois dias depois pelos traficantes que já atuavam no local. Esse "pouco mais de um dia" provocou em boa parte dos moradores um conflito interno, motivado pela incerteza do que poderia acontecer com um novo "comando"3 local. Ao externalizarem esse conflito nos seus discursos e narrativas, acabaram por relatar, por meio da comparação entre esses dois grupos, sua representações sobre os mesmos de forma bastante sistemática.

${ }^{2}$ Os termos tomada e retomada, usados constantemente pelos entrevistados, foram interpretados por esse pesquisador como categorias nativas, que fazem muito sentido quando lidas à partir do imaginário da violência urbana carioca, marcado pela "metáfora da guerra" (LEITE, 2000).

3 Categorias como "comando", "domínio" foram bastante utilizadas pela imprensa (e seu uso se estendeu ao imaginário da violência no Rio de Janeiro) para indicar que nas favelas os grupos de traficantes de drogas teriam assumido um papel de governo das atividades locais, tomando o lugar que seria por direito do Estado (que tem o uso legitimo da força). Para definir essa forma de poder, criou-se outra categoria, também bastante utilizada: "poder paralelo". No entanto, percebe-se a falácia dessas terminologias ao se constatar que, primeiramente, o estado nunca esteve ausente das favelas - mesmo que tenha marcado sua presença nesses espaços por oferecer políticas públicas de forma deficitária - , e depois, essas fronteiras entre legal e ilegal são bem mais complexas do que se apresentam à percepção geral (TELLES, 2010), exigindo uma análise mais pormenorizada das relações entre o Estado, a população e esses grupos marginais.

Idéias - Rev. Inst. Filos. Ciênc. Hum. UNICAMP, v.6, n.2, p.195-224, jul/dez. 2015 
A principal técnica utilizada para a coleta dos dados que serão analisados foi a realização de entrevistas aprofundadas com cinco pessoas, escolhidas por terem acompanhado o episódio de forma privilegiada, o que permitiu aguçar suas percepções e descrever melhor as representações em questão.

\section{1 - A Cidade Alta e sua sociabilidade violenta}

A Cidade Alta $^{4}$ é um sub-bairro do bairro de Cordovil, localizado na Zona Norte do Rio de Janeiro, próximo à fronteira da cidade com a região conhecida como Baixada Fluminense. Sua população é de aproximadamente 40 mil moradores e sua origem remete ao ano de 1969, com a construção do seu primeiro e principal conjunto habitacional: o conjunto Cidade Alta. Logo em seguida, foram construídos, no mesmo local, outros dois conjuntos habitacionais e três favelas. O conjunto habitacional Cidade Alta foi o resultado das políticas públicas de remoção de favelas implementadas nas décadas de 1960 e 1970 na cidade do Rio de Janeiro. Tais políticas tinham por objetivo a extinção da favela enquanto espaço habitacional e ambiente de mobilização social e teve como consequência a transferência de um número significativo de moradores de favelas da zona sul da cidade para conjuntos habitacionais construídos em regiões periféricas, tais como a Cidade Alta. O conjunto foi inaugurado em março de 1969, sendo seus primeiros habitantes, em sua grande maioria, ex-moradores removidos da extinta Favela da Praia do Pinto, no bairro do Leblon, erradicada após sucessivos incêndios.

A presença de grupos armados e do comércio de drogas, segundo os moradores mais antigos, os acompanha desde a favela da Praia do Pinto, e estão presentes na Cidade Alta desde a sua fundação. Porém, na década de 90, percebe-se um fenômeno social

${ }^{4}$ Utilizarei o nome Cidade Alta para me referir ao sub-bairro, e conjunto habitacional Cidade Alta para me referir ao primeiro conjunto inaugurado neste local. 
de grande força no contexto desse território: um crescimento do poder de intervenção desses grupos armados sobre esse espaço, seu cotidiano e seus moradores. O mesmo fenômeno ocorria, a partir da década de 90, em diversas favelas cariocas. E essa nova configuração do tráfico de drogas, segundo Leite,

\begin{abstract}
levou ao "desencapsulamento" do crime violento, que antes se situava em áreas menos acessíveis das favelas e era desinteressado da vida local, e passou a envolver o controle militar aberto e sem disfarce do território e a submissão das organizações de base a suas ordens e seus desígnios, esvaziando-as de base social e legitimidade. (LEITE, 2008: 119)
\end{abstract}

Essa nova conjuntura levou os moradores das favelas cariocas a adotarem uma nova forma de conduta baseada em uma sociabilidade violenta. Esse conceito é utilizado por Machado da Silva (2004) para designar um conjunto de representações e práticas que se expressa em uma ordem social, marcada por condutas de submissão das pessoas diante do uso da força por parte dos agentes da criminalidade violenta. Por mais que esteja presente em toda a cidade, afetada pela violência urbana, é nas favelas que ela apresenta sua expressão mais forte. Os moradores das favelas com a presença ostensiva de grupos armados assumem, na maioria das vezes, uma condição submissa diante dos seus agentes para garantir uma convivência sem problemas ou demais consequências. Descrevendo esse processo, o autor apresenta o seguinte cenário:

O que permite coordenação entre as condutas, formando um complexo orgânico de relações sociais (e uma visão de mundo que é compartilhada, porém sem envolver intersubjetividade), é justamente o reconhecimento da resistência material representada pela força de que podem dispor os demais agentes, produzido pela reiteração de demonstrações factuais, e não por acordo, negociação, contrato ou outra referência comum compartilhada. Todos obedecem apenas porque e enquanto sabem, pela demonstração 
do fato em momentos anteriores, que são mais fracos, com a insubmissão implicando necessariamente retaliação física quase sempre letal (MACHADO DA SILVA, 2008: 42).

Na Cidade Alta, a atuação do tráfico de drogas chamava a atenção para a presença de um antigo "chefe" (como são chamadas as lideranças locais desses grupos armados), chamado por todos de Mineiro ${ }^{5}$, que por mais de 20 anos manteve-se a frente das atividades coordenadas pelo Comando Vermelho nesta localidade. Tanto pelo poder bélico como por sua personalidade ${ }^{6}$, conseguiu ser reconhecido como uma verdadeira autoridade local pelos moradores da Cidade Alta. Um rito que demonstrava o reconhecimento dessa autoridade se dava quando uma nova diretoria da Associação de Moradores, eleita pela população local, precisava dirigir-se ao chefe do tráfico (no caso, o Mineiro) para receber as chaves da sede da Associação, assim como deveriam entregá-las ao término do mandato. Tal rito de passagem deixava claro que a representatividade dos moradores pela associação atuaria dentro de uma série de proibições e permissões definidas pelo líder local do tráfico 7 .

Toda a sociabilidade na Cidade Alta era, naquele momento ${ }^{8}$, marcada pelo tráfico e suas "regras" e "autoridades". Mas apesar dos desconfortos causados por essa forma de sociabilidade, é preciso ressaltar que os moradores já dominavam essas regras demarcadas pela sociabilidade violenta, e como há muito tempo

\footnotetext{
${ }^{5}$ Tratava-se do traficante Gilberto Martins da Silva, reconhecido como uma das mais antigas lideranças do Comando Vermelho. Foi morto pela polícia, aos 46 anos de idade, em 05 de outubro de 2008.

${ }^{6}$ Mineiro, assim como outros líderes do tráfico carioca, foram reconhecidos por um certo carisma junto à população na condução de suas atividades.

${ }^{7}$ Sobre a inibição do papel das associações de moradores diante da atuação do tráfico, ver cf. ROCHA \& SILVA, 2008.

${ }^{8}$ Refiro-me a fevereiro de 2007, período em que a milícia tentou "tomar" a Cidade Alta.
} 
não presenciavam uma troca de "chefe", incorporaram tais regras em seus cotidianos. Uma troca de "chefe" ou de "comando" poderia trazer grandes mudanças, positivas ou não, mas que certamente provocariam uma alteração dessas rotinas, e mesmo

que tal alteração fosse desejada por alguns, era temida por sua incerteza, característica presente em qualquer tipo de mudança.

\section{2 - Tráfico e milícia: fenômenos da violência urbana carioca}

Pretendo descrever, brevemente, as discussões sobre a história e o papel desses grupos armados na configuração da violência urbana carioca e de que forma se colocam em disputa, não só nos confrontos armados, mas também nas representações presentes no imaginário dessa violência urbana.

Chamamos por "tráfico" aqueles grupos armados que atuam ostensivamente nas favelas cariocas e que têm como atividade principal o comércio ilegal de drogas, entre tanta outras. No Rio de Janeiro e cidades vizinhas, grande parte dos traficantes de drogas estaria agrupada em três redes de apoio formadas e sustentadas a partir dos presídios: Comando Vermelho (CV), Terceiro Comando (TC) e Amigos Dos Amigos (ADA). Esses grupos são geralmente rivais e disputam entre si o domínio desses territórios. Sua ação vai para além da venda de drogas: hoje esses grupos conseguem controlar, por meio do uso da força, grande parte das atividades e da sociabilidade local, criando uma ordem social caracterizada pela sociabilidade violenta, como observei anteriormente.

As estruturas atuais do narcotráfico carioca teriam início, segundo Leeds (2004), na convivência entre presos políticos e assaltantes comuns no presídio de Ilha Grande durante a década de 70. Porém, passaram a ter maior influência e visibilidade a partir da década de 90, quando tais organizações (que passaram a ter altos ganhos com a comercialização da cocaína) compraram armamentos sofisticados em grande quantidade, o que aumentou a força destas e desencadeou um esquema de dominação dos 
criminosos às favelas e seus moradores que perdura em muitas delas até hoje.

A partir desse período, a cidade do Rio de Janeiro passa a ser conhecida e reconhecida como uma cidade violenta (em oposição à "cidade maravilhosa"), representação gestada a partir de uma série de episódios violentos ocorridos no início da década de 90., Fatos como a melhora do armamento dos traficantes de drogas e a ocupação ostensiva das favelas tiveram grande importância na construção desse imaginário. A cidade passou a ser considerada como "partida" entre favela e asfalto e seu imaginário foi dominado por uma metáfora da guerra (LEITE, 2000), que acabou por agravar o problema da violência na cidade. Segundo Leite,

As novas modalidades de violência presentes no Rio de Janeiro a essa época associavam-se às dinâmicas do tráfico de drogas e armas e aos inúmeros confrontos entre policiais e traficantes e entre quadrilhas rivais de traficantes entrincheiradas nos morros e favelas da cidade. De lá parecia emergir um "mal" a se irradiar para a cidade. A percepção da ineficiência das políticas públicas de segurança e a vivência, por uma parte de seus moradores, de situações características de contextos de guerra (mortes, trocas de tiros, invasões etc.) no espaço urbano propiciaram o desenvolvimento de uma "cultura do medo" que redefiniu as relações dos cariocas com o território urbano e com seus concidadãos, alterando-lhes a sociabilidade. A cidade outrora tida como aberta e hospitaleira encheu-se de portões, guaritas e grades, bem como de seguranças e de vigias. $\mathrm{O}$ tema da violência também adquiriu centralidade na pauta da mídia e dos políticos na cidade. (LEITE, 2000:74)

A cultura do medo (cunhada em um Rio de Janeiro que se crê em guerra), a qual Leite se refere, tem nas favelas o objeto do seu temor, o seu grande inimigo. As ressalvas aos criminosos do tráfico de drogas são estendidas aos moradores desses espaços como um todo e que juntam a uma série de estigmas historicamente remetidos 
à favela e aos seus moradores as acusações de cumplicidade ou participação direta com a atividade criminosa. Para os "favelados", especialmente os mais pobres e negros, intensifica-se o processo de sujeição criminal $^{9}$ (MISSE, 2008). Mas voltando a metáfora da guerra, a imagem da criminalidade presente nas favelas foi de tal modo incorporada a esses espaços e seus moradores que

[...] se vivia de fato uma guerra que opunha morro e asfalto, favelados e cidadãos, bandidos e policiais, os partidários desta perspectiva aceitavam a violência policial em territórios dos e contra os grupos estigmatizados e assistiam passivos ao envolvimento de policiais militares em várias chacinas (LEITE, 2000: 75).

A cidade tornou-se cada vez menos receptiva aos "favelados", confinando os mesmos, junto com os criminosos, dentro das favelas. $\mathrm{O}$ "tráfico", tentando amenizar os problemas dessa convivência tensa, intensificou (por razões instrumentais) nas favelas em que atuavam uma regulação marcada por uma série de regras de convivência, que de uma certa forma diminuía parte do sentimento de insatisfação dos seus habitantes. Ao proibir, por exemplo, roubos, matanças e estupros nesses locais, com punições severas para os infratores, criaram um sentimento de segurança

${ }^{9}$ Tal conceito, desenvolvido por Misse, parte do seguinte princípio: “Quando a incriminação se antecipa à criminação (e mesmo à criminalização) de forma regular e extra-legal, isto é, quando se passa diretamente da acusação à incriminação, mesmo sem que qualquer evento tenha sido 'criminado', isto é, interpretado como crime, temos então que o foco se desloca do evento para o sujeito e do crime para o virtual criminoso [...]. Para distinguir esse processo social de um processo de incriminação racional-legal, chamo-o de 'sujeição criminal'. Nele, primeiramente, busca-se o sujeito de um crime que ainda não aconteceu. Se o crime já aconteceu e se esse sujeito já foi incriminado antes, por outro crime, ele se torna um 'sujeito propenso ao crime', um suspeito potencial. Se suas características sociais podem ser generalizadas a outros sujeitos como ele, cria-se um 'tipo social' estigmatizado" (MISSE, 2008: 380). 
interna, bem representado por frases do tipo "na favela, você pode dormir de porta aberta que ninguém vai roubar sua casa", muitas vezes citadas por seus moradores. Esse sentimento de segurança, mesmo que fruto de uma violência extralegal, foi percebido como um benefício dessa presença ostensiva (diante do desastroso histórico de políticas públicas de segurança oferecidas pelo Estado), até por parte dos moradores que, por motivos práticos, ideológicos ou morais, não aceitavam a presença dos agentes do tráfico.

Já quando nos referimos a milícia ${ }^{10}$, parece que estamos lidando com uma realidade um pouco mais plural que a realidade do tráfico de drogas. Este termo, segundo Cano e Loot (2008)

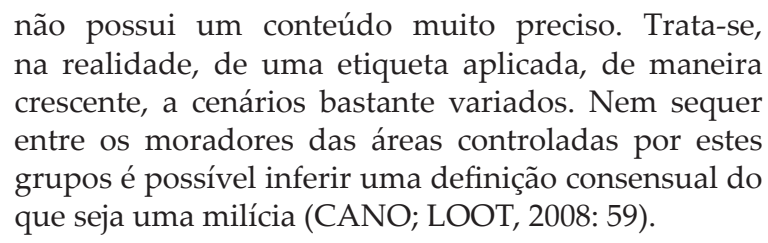

Mesmo diante desse impasse conceitual, o que se denomina geralmente como milícia são grupos compostos por policiais e outros agentes do estado, e que passaram a dominar áreas anteriormente controladas por traficantes. Na maior parte dos casos, mantêm as suas atividades não mais pelo comércio ilegal de drogas (como o "tráfico"), mas pela cobrança de uma taxa a moradores e comerciantes - justificada por uma suposta proteção -, e no controle de outras atividades informais como distribuição de TV a cabo e internet, venda de bujão de gás e transporte alternativo.

Alguns autores como Misse (2008) e Alves (2008) remontam a origem das práticas da milícia aos "esquadrões da morte" e "grupos de extermínio", que surgiram na década de 50, período que Misse (2008) apresenta como inicial da acumulação social da violência no Rio de Janeiro. Tais grupos surgem na cidade do Rio de Janeiro e, mais fortemente, na Baixada Fluminense como

\footnotetext{
${ }^{10} \mathrm{O}$ termo "polícia mineira" também é utilizado para referenciar tais grupos.
} 
grupos de "justiceiros", que caçam os criminosos e os exterminam em nome da manutenção da ordem e da paz. Os líderes desses grupos se tornaram populares e suas práticas foram percebidas por muitos como heroicas. Tiveram seu auge nas décadas de 70 e 80, de forma mais incisiva na Baixada Fluminense, sendo patrocinados por políticos e empresários em suas ações de limpeza e extermínio. Esses grupos de extermínio eram formados na sua grande maioria por policiais, ex-policiais, guardas municipais e bombeiros.

Na década de 1990, enquanto o Rio de Janeiro assistia à forte expansão do comércio de drogas ilícitas e ao controle dos seus agentes sobre várias favelas, na Baixada Fluminense, vários membros de grupos de extermínio (ALVES, 2008) ascendiam ao poder, tornando-se vereadores, prefeitos e deputados. Diante disso, cansados de serem apenas mediadores na economia política do crime que gera bilhões no Rio de Janeiro, membros do aparato policial passaram a estabelecer o seu próprio controle das áreas, a partir do que passou a se denominar de milícias (ALVES, 2008: 34).

A primeira década do século 21 presenciou a entrada de grupos com o perfil semelhante ao dos grupos de extermínio da baixada fluminense em diversas favelas e bairros populares do Rio de Janeiro, de forma mais concentrada na zona oeste da cidade. Foi 2006 o ano em que se proliferou por um maior número de localidades e quando tornou-se um fenômeno amplamente visível. Com a atenção da mídia, ampliaram sua visibilidade e passaram a ser conhecidos e reconhecidos como Milícias. Nesse mesmo ano, tais grupos são apresentados pela mídia e por alguns políticos como práticas louváveis de autodefesa comunitária.

A aparente avaliação positiva da qual as milícias gozavam em 2006, que permitiu a eleição de vários representantes desses grupos, passou a declinar a partir de meados de 2007, principalmente por conta das denúncias de abusos e torturas contra moradores e da prisão de alguns dos seus principais líderes. Em maio de 2008, veio o golpe final contra a boa imagem que a milícia gozava, com ampla repercussão na opinião pública: a tortura contra jornalistas do jornal "O Dia", que realizavam uma investigação jornalística na favela do Batan, em Realengo. 
As disputas entre tráfico e milícia se dão constantemente no campo das representações: ambos disputam significados presentes no imaginário da violência urbana, trabalhando com categorias de acusação que justificam a legitimidade de um grupo por meio da impugnação do outro: bandido, herói, organizado, caótico, explorador, defensor, morador, intruso etc. Apesar de algumas dessas categorias serem mais comumente aplicadas a um desses grupos, podem, dependendo do ponto de vista ou do contexto, ser aplicadas ao grupo rival.

\section{3-O episódio: a "tomada" e "retomada"}

O que apresento a seguir inspira-se nos relatos das entrevistas que fiz e nas notícias veiculadas pelas mídias (jornais, TV e internet) na semana seguinte aos acontecimentos. Procuro, de forma resumida, destacar os detalhes mais significativos desse episódio.

Era uma noite de sexta-feira (02/02/2007), perto da meianoite. A quadra do Barriga ${ }^{11}$ recebia o show de um popular artista da MPB. O evento estava lotado, mesmo que alguns aspectos denunciassem que o bairro não experimentava seu cotidiano com a mesma normalidade de sempre. Os mais atentos ainda estavam ressabiados com os eventos da madrugada de quinta para sexta: uma intensa troca de tiros por horas entre os policiais militares e os oficiais do BOPE (com direito à presença do "caveirão"12) contra os traficantes do Comando Vermelho que atuavam na localidade.

De repente, de forma discreta, homens de colete preto entram na quadra e pedem para falar com o presidente do bloco. $\mathrm{O}$ papo, a princípio privado, se espalha rapidamente entre todos os presentes: trata-se de um miliciano, que comunicou ao presidente

\footnotetext{
${ }^{11}$ Refere-se à quadra do Bloco carnavalesco do Barriga, na Cidade Alta.

${ }^{12}$ Nome dado ao veículo blindado utilizado pelo BOPE (Batalhão de Operações Especiais da Polícia Militar do Rio de Janeiro).
} 
que a partir de então a milícia seria "responsável" pela Cidade Alta. Sem alarde se retiraram do local, deixando em todos uma expectativa diante do que iria acontecer daí para frente. Mais tarde, em função de um tiroteio, outros homens de colete preto entraram correndo na quadra, assustando os presentes. Logo depois, foram embora novamente, e o show continuou pela madrugada.

No dia seguinte, o bairro apresentava uma rotina ainda mais diferenciada. Os "milicianos" se inseriam no cotidiano, provocando estranheza aos moradores. Homens de colete preto, em grande quantidade, se faziam destacadamente presentes no local, circulando em carros e motos ou fazendo guarda em alguns pontos estratégicos. Paravam carros suspeitos, se apresentavam aos moradores, e tudo isso de forma bastante educada, conforme os relatos. O serviço de "Kombis" e "moto-táxi" (formas de transportes alternativos bastantes presentes nas favelas cariocas), assim como boa parte do comércio, não funcionaram nesse dia.

Mas algo inesperado aconteceu. No domingo, nas primeiras horas do dia, quando os feirantes arrumavam suas barracas para a tradicional feira dominical do bairro, iniciou-se um novo confronto entre traficantes e milicianos. O confronto se estendeu por boa parte da manhã, de forma intensa. Os moradores que estavam próximos aos locais do confronto passaram boa parte deste tempo abrigados em cômodos de seu apartamento que não seriam tão vulneráveis a receber uma bala perdida, como o corredor, banheiro e a cozinha. Outros, mais curiosos, acompanhavam por uma fresta da janela parte dos acontecimentos.

A batalha terminou com a vitória dos traficantes e uma promessa de retorno por parte dos milicianos que até hoje não se concretizou $^{13}$. Segundo os moradores, a vitória no confronto se deu principalmente pelo conhecimento dos traficantes da geografia

${ }^{13}$ Notícias sobre um possível retorno da milícia foram publicadas no site Terra: Milícia recruta homens para novo ataque no Rio. Texto disponível em: http:// noticias.terra.com.br/brasil/noticias/0,,OI1397975-EI316,00-milicia+recruta+h omens+para+novo+ataque+no+Rio.html. Texto de Fevereiro de 2007. Acesso em $21 / 07 / 2011$. 
local, em especial dos muitos becos existentes entre os prédios, de onde iniciaram o confronto. Também utilizaram os terraços dos prédios como espaços privilegiados para os seus ataques.

No domingo à tarde, após algumas mortes e muitas marcas de tiro nas paredes de alguns prédios residenciais, comércios e instituições públicas, os agentes do tráfico de drogas "retomaram" - assim diziam os nativos - o espaço e suas atividades. Os moradores, surpresos com os últimos acontecimentos, retomavam a nova-velha rotina, marcada pelos efeitos da sociabilidade violenta na relação com os traficantes.

\section{4 - Analisando as entrevistas}

A principal técnica utilizada para a coleta dos dados aqui analisados foi a realização de entrevistas aprofundadas com cinco pessoas, com quem já mantenho contato por conta de trabalho de campo que venho realizando na Cidade Alta há alguns anos ${ }^{14}$. Essas pessoas foram escolhidas por terem acompanhado os confrontos iniciais e finais desse evento de forma privilegiada (principalmente por conta da proximidade de sua moradia aos locais de confronto ou por uma observação mais apurada de alguns fatos), o que permitiu aguçar as percepções e descrever melhor as representações em jogo.

Os entrevistados serão identificados com nomes fictícios por uma questão de segurança. Apresento agora um perfil resumido de cada um deles: Celma: 34 anos, nível superior, casada, mora na Cidade Alta desde que nasceu, casada e mãe de um filho de 8 anos. Fábio: 27 anos, solteiro, concluindo o ensino superior, mora na Cidade Alta também desde que nasceu. Gilmar: 65 anos, tem o antigo primário incompleto, aposentado, mora no Conjunto Cidade Alta desde a sua fundação, casado, tem 2 filhas. Sônia:

\footnotetext{
${ }^{14}$ Sou morador desse espaço da cidade e desenvolvo pesquisas etnográficas
} nele desde 2005. 
42 anos, tem o ensino médio completo, casada, tem uma filha, mudou com os pais para o conjunto Cidade Alta quando ainda era criança. Zélia: 56 anos, viúva, mãe de dois filhos, tem o antigo ginásio incompleto, mudou-se ainda adolescente para a Cidade Alta, poucos anos depois da fundação do primeiro conjunto habitacional.

Um elemento presente em todas as entrevistas foi a afirmação, por diversas vezes repetidas, de que não tinham "lado" nessa disputa, mesmo que manifestassem alguma preferência em determinados momentos. A definição dos agentes locais do tráfico de drogas, por exemplo, era sempre acentuada por termos que sugerem uma certa distância: "eles", "os bandidos", "os vagabundos"15. Acentua-se mais uma distância moral do que física.

Quando a gente viu que tudo tinha voltado ao normal... as pessoas, os bandidos que a gente via diariamente, os donos da época... então, se viu que tudo voltou ao normal. (Celma)

Uns falavam preferir que eles ficassem, dizendo que ia melhorar, outros queriam que os próprios vagabundos daqui ficassem, entendeu? Então, assim, cada uma tinha uma opinião de maneira diferente. (Sônia)

Fica claro ainda o reconhecimento, por parte desses moradores, dos traficantes enquanto criminosos, expressando aí uma representação que implica em, mais do que apontar uma condição ilegal, entender o sujeito assim identificado como alguém imerso em um universo moral totalmente distinto do trabalhador ${ }^{16}$.

${ }^{15}$ Essa postura de separação e afastamento também foi observada em outros trabalhos de campo, conforme demonstram Machado da Silva e Leite (2007: 556): “Os moradores não só reconhecem que as quadrilhas de traficantes fizeram das favelas um local de violência, como deles fazem questão de se separar, como indica o uso frequente das categorias 'nós' versus 'eles' (ou 'o cara', 'vagabundo', 'marginal', etc.) e 'lá' [na 'boca de fumo'] versus 'aqui' [na 'comunidade']".

${ }^{16}$ A pertença ao mundo do trabalho atesta, para as camadas populares, a 
Quanto aos milicianos, apesar de todos os entrevistados reconhecerem que estes também formam um grupo criminoso, não o representam pelas mesmas categorias, mesmo que por vezes as utilizem para comparar a milícia com o tráfico de drogas. Os termos milícia ou milicianos são utilizados muitas vezes ao lado de "bandido(s)" na tentativa de diferenciá-los dos traficantes:

E eles fizeram questão de fazer um estardalhaço, buzinar, eram muitos homens na Pickup, não dava pra saber se eram bandidos. A imagem que se tinha.... a gente sabia que era mílicia, mas poderia passar tranquilamente como bandido, por que estavam lá armados, com roupa comum, e não tinham assim uma postura militar.(Celma)

Se eu não me engano ou foi de sábado pra domingo ou de segunda pra terça.... não, é domingo pra segunda... não lembro muito bem, que foi quando aconteceu outro intenso tiroteio, no qual os bandidos da Cidade Alta reagiram a milícia. Como eles conhecem muito a localidade da Cidade Alta conseguiram empurrar os milicianos. (Fábio)

Diante do reconhecimento de ambos como grupos criminosos, o uso de categorias distintas se justifica, pois esses

diferenciação em relação aos bandidos e criminosos. Estes são percebidos como aqueles que rejeitam a identidade e a dignidade possibilitadas pelo trabalho. Segundo Zaluar, "Para os trabalhadores, o bandido é a pessoa atraída pelo dinheiro fácil, que não quer trabalhar, que tem maus vícios quando comparado ao trabalhador que fala ou a alguém da sua família... Esta ética do trabalho não advém, para os trabalhadores daqui, do valor moral da atividade em si. É a ética do provedor de sua família, que permite ao trabalhador sentir-se no seu íntimo e aparecer em público como moralmente superior aos bandidos" (ZALUAR, 2000: 145). A utilização da frase "eu sou trabalhador", de uso corrente entre os moradores de favela quando esses são abordados pela polícia, quer expressar essa superioridade moral concedida por essa identidade. O uso de tal frase permite a diferenciação e molda a sociabilidade iniciada, invocando o uso dos padrões esperados para a identidade invocada. 
atores sociais entendem que a diferença central desses agentes está nos valores que tais grupos sustentam (ou parecem sustentar). Dos cinco entrevistados, três deles (Celma, Fábio e Zélia) disseram que queriam a permanência da milícia no local em vez dos traficantes, enquanto os outros dois (Sônia e Gilmar) não tinham esperanças de melhoras e preferiam a permanência dos "bandidos" por conta de uma rotina já estabelecida, da qual eles tinham domínio. Porém, a rejeição dos últimos não é à milícia enquanto instituição, mas ao perfil de milícia que se apresentava para a Cidade Alta que, segundo os mesmos, era desqualificada por ser formada por "exbandidos":

A milícia já existe há muito tempo. Lá em Jacarepaguá, em Rio das Pedras, é uma beleza de se morar. Não se vê ninguém armado, ninguém fuma maconha no beco... Então, a gente torcia pra eles virem pra cá pensando que era isso, só que essa milícia que invadiu aí é bandido igual aos outros. (Gilmar)

Sinceramente, foi isso que eu pensei, não sei se seria melhor com eles ou sem eles, entendeu? Por que as milícias de hoje em dia, não são como a do Rio das Pedras ${ }^{17}$. As milícias daqui são tudo bandido, bandido daqui mesmo da Cidade Alta, que é expulso daqui, vai pro Quitungo ${ }^{18}$ e se torna miliciano. Já conhece a área todinha, entendeu? Então, não faz muita diferença não. (Sônia)

A milícia é percebida por essas pessoas como uma opção mais viável, mesmo que rejeitem as experiências mais próximas, por se afastarem de um modelo ideal (como seria Rio das Pedras para Gilmar e Sônia).

Vale lembrar que, mesmo que as entrevistas tenham sido feitas em 2012, as pessoas procuraram recuperar suas memórias

${ }^{17}$ Favela na região de Jacarepaguá (zona oeste da cidade).

${ }^{18}$ Bairro próximo à Cidade Alta onde os milicianos estão presentes.

Idéias - Rev. Inst. Filos. Ciênc. Hum. UNICAMP, v.6, n.2, p.195-224, jul/dez. 2015 
de 2007, período em que ocorreu o episódio, quando as impressões positivas sobre a milícia (sua descrição como uma forma de "autodefesa comunitária") povoavam o imaginário da cidade e desses moradores. Mesmo assim, a milícia só foi percebida como uma boa opção diante de dois dilemas: a presença ostensiva do tráfico de drogas e um possível descaso da política de segurança pública para com as necessidades da Cidade Alta e das favelas como um todo:

É claro que não se quer que seja assim, gostaríamos que a polícia viesse, que fosse um sistema organizado dentro da comunidade, prendendo quem tem que se prender, cuidando das pessoas que são viciadas.... enfim... mas qualquer melhoria, dentro de uma comunidade que está à margem é sempre benéfica. Então as pessoas tinham a mesma perspectiva que a minha, de que talvez melhorasse alguma coisa com a milícia. (Celma)

Pelo esquema que já era aqui, qualquer tipo de coisa que pareça um pouco mais justa, pra quem é de bem, tá melhor. Por mais que não seja polícia, se tinha pelas outras comunidades que a gente via no jornal ... e se apresentava pra gente de uma forma um pouco mais justa pra comunidade. Acredito que entre uma não entrada efetiva do Estado por meio da polícia, se tem um miliciano que trataria a comunidade com um pouco de mais respeito, claro que é um respeito não verdadeiro... digamos, um pouco mais de consideração, era melhor. Infelizmente durou pouco. (Fábio)

Mas, quais seriam os valores que permitem a esses moradores, que se autodefinem como "pessoas de bem"19, uma

\footnotetext{
${ }^{19}$ Cano e Loot (2008: 65) apresentam, a partir de um exemplo, como são estreitas as relações entre as opções morais e as representações sobre esses grupos: "Muitos moradores, particularmente os que rejeitam as drogas por um imperativo moral, como por exemplo muitos evangélicos, de fato incorporam esta visão da milícia como um mal menor".
} 
maior identificação com a milícia, percebendo-a como um mal menor? Elenco aqui, partindo destas entrevistas, três oposições apresentadas em um contexto de disputa de significados que acabam por revelar esses valores, que levam esses atores sociais a aproximar ou afastar a milícia e o tráfico do seu universo de opções morais e existenciais:

a) Ordem versus desordem

Primeiramente, vale uma definição do conceito de ordem, a partir das representações ativadas pelos informantes. Ordem, que para eles parece algo óbvio e dado, é uma categoria utilizada para expressar um plano de sociedade que funcione conforme uma moral cristã tradicional (pelo menos no campo dos valores), onde as leis sejam obedecidas e que seja livre de conflitos. Logicamente, o conceito de ordem varia de indivíduo para indivíduo, assim como as concepções do que é legal/ ilegal e moral/imoral. Mas, podemos dizer que há um consenso na interpretação de que a ordem é uma configuração do ambiente ideal para as "pessoas de bem", e certamente muito diferente do contexto que vivenciam na Cidade Alta.

Muitas das declarações trouxeram à tona a crença de que a milícia seria capaz de construir a ordem (pelo menos em parte) regulando as práticas da sociabilidade local, permitindo com que o ambiente se tornasse mais propício para as "pessoas de bem":

Eu achei que ia melhorar. Porque pelo menos a gente não ia ter que aturar esses chincheirinhos ${ }^{20}$ aí, abusando, fumando maconha na cara da gente. Pelo menos isso, já que o governo não faz a parte dele, a gente não pode contar com o governo pra ordem, né? Então, pelo menos, já que a gente vive em um lugar que é comandado por bandido, pelo menos que fosse um bandido mais organizado, que não tivesse tráfico de drogas. (Zélia)

${ }^{20}$ Refere-se aos usuários de cocaína. 
Aquele baile funk ali, quem mora naquele prédio ali, dia de sábado e domingo não dorme. Por que é alto mesmo, de sacudir e quebrar a vidraça. Aqui, todo sábado e domingo tem baile. Tem um cara de um bar ali que tem duas caixas de som, é música alta a noite toda. Aí os crackudos ${ }^{21}$ ficam dançando. Seis horas da manhã o som tá ligado ainda. O esquema daqui é muito abusado. Os caras botam um som aí, vai a noite toda, e é alto mesmo. Na área do miliciano isso não iria acontecer. (Gilmar)

A gente tinha relatos de outras comunidades de que a milícia estava dando certo. É claro que eu sei que é só uma troca de poder, mas, pelo menos, pelos relatos que a gente sabe, de lugares que tem milícia, não tem esse uso tão escancarado de drogas. Existe uma lei, entre aspas, mais efetiva. Então, era uma troca de bandido por bandido, porém, pelo o que a gente sabia de outras comunidades, que tinha mais uma lei sendo gerada, constatada, no dia-a-dia da comunidade.... aqui na comunidade as pessoas usam drogas a luz do dia, na frente dos filhos da gente, então não se tem respeito. As pessoas andam armadas, a gente tem que passar com a pessoa armada do lado. E assim, a gente não sabia como é que ia ser aqui, mas pelo relato que a gente tinha, em outras lugares isso era amenizado, isso não existia. Então, só em não ter essa imagem, essa presença tão efetiva de drogados, de homens armados, dá uma certa tranquilidade. (Celma)

A figura do miliciano ordenador, contrária à do traficante que deixa o caos acontecer, é o elemento que, junto com a promessa de segurança (também profundamente ligada à ideia de ordem neste contexto), justifica a cobrança de taxas por parte dos milicianos, como defende Misse:

${ }^{21}$ Refere-se aos usuários de crack. 
O fenômeno das "milícias" ganhou maior visibilidade com as invasões organizadas de favelas e conjuntos habitacionais a partir de 2006 por grupos de trinta a quarenta policiais militares. Após afastarem os traficantes da área, instalavam ali de quatro a oito policiais que passavam a exigir uma "contribuição" dos moradores para a manutenção da "ordem" (MISSE, 2007:154).

Não se pode deixar de ressaltar que essa função de manter a ordem foi muitas vezes exercida pelos grupos de traficantes nas favelas cariocas, mas, como ressalta Cano e Loot,

\begin{abstract}
Vale frisar que o narcotráfico tradicionalmente também preenche essa função de regular a vida social e garantir uma ordem interna, e recebe inclusive por isso um certo apoio e legitimidade por parte das comunidades, pelo menos naquelas em que a ordem é menos tirânica e arbitrária. A diferença é que o tráfico, pelo menos no que poderíamos considerar o tipo ideal de narcotráfico nas favelas cariocas, não pretende se legitimar por isso nem aspira a que isso seja um traço central da sua definição [...]. De alguma forma, eles assumem que o que eles fazem é "errado" (CANO;LOOT, 2008: 66).
\end{abstract}

Além do mais, no universo de representações dos entrevistados em questão, o usuário de drogas - o "maconheiro", o "chincheirinho" e o "crackudo", por exemplo - é o agente provocador da desordem por excelência. O traficante não pode aspirar ao papel de ordenador enquanto alimentar os vícios desses usuários. O relato a seguir clarifica tal concepção:

Ontem nós vimos um garoto apanhando (referia-se a um usuário de crack), e os vagabundos batiam no garoto por causa de uma bermuda que ele roubou, pegou aqui na corda. Aí, o outro ia dar tiro no joelho dele, na frente dos moradores, e então a vizinha daqui 
de cima segurou esse vagabundo e levantou a arma dele pro alto, por que ele ia dar tiro na frente de todo mundo. A vizinha falou: "Vocês não devem bater nele não, por que vocês que são culpados, vocês que tão vendendo essa droga pra ele". (Sônia)

b) Policial (lei) versus Bandido (crime)

Mesmo reconhecendo os milicianos enquanto criminosos, diante dos traficantes esses parecem ser uma opção mais viável, principalmente quando estão em jogo valores como legalidade e justiça. Um dos fatores que justifica tal predileção é a presença (ou a crença na presença) de policiais nas milícias. O miliciano é alguém que mesmo agindo de forma extralegal se coloca como um agente da lei, e mesmo diante desta atividade ilegal - quando for um agente estatal, como muitos são - é alguém imerso no mundo da legalidade ${ }^{22}$. O traficante, ao contrário, é assumidamente ligado ao mundo do crime, que é reconhecido (e por vezes assim se reconhece) como "poder paralelo", como contra a ordem vigente. As entrevistas revelam como os atores sociais avaliam, positiva ou negativamente, os grupos de milícia pela presença ou ausência de policiais, assim como das suas atitudes e hábitos:

No outro dia, eles fizeram um grande movimento, fizeram questão de se mostrar, com as pick-ups, andando na comunidade. Uma impressão muito negativa ficou pra mim, porque eles não estavam uniformizados, estavam com roupa comum, mas a gente via que era realmente a milícia, e realmente nos passou um grande medo. Eles fizeram questão de fazer um estardalhaço, buzinar, eram muitos homens na Pick-up, não dava pra saber se eram bandidos. A gente sabia que era milícia, mas poderia passar

22 “Em primeiro lugar, é justamente o pertencimento ao estado que serve como alavanca, mesmo em situação irregular, para a tentativa de legitimação das milícias. Na medida em que seus membros são agentes do estado, são a representação da autoridade, ganharia sentido o seu discurso de se opor à criminalidade" (CANO; LOOT, 2008: 67). 
tranquilamente como bandido, por que estavam lá armados, com roupa comum, e não tinha assim uma postura militar. (Selma)

A ausência do uniforme e da postura militar, aspectos a princípios superficiais no ethos policial, ganham peso na construção das representações da milícia por não permitirem a diferenciação imediata para com os bandidos. Já o trecho a seguir coloca a formações de grupos mistos de milicianos (com outros agentes além daqueles das forças militares) como algo que deteriora o grupo e suas intenções:

Se eles ficassem aqui seria muito diferente. Porque, é como eu falei, os milicianos de hoje a maioria é tudo bandido, bandido que é expulso das comunidades e que se torna miliciano. Entendeu? Antigamente era só a polícia, mas agora não é a só a polícia não, agora também tem bandido no meio. (Sônia)

É interessante perceber a presença da polícia como uma referência positiva na formação da imagem desses grupos, já que no contexto das favelas cariocas muitos dos seus moradores alimentam representações negativas sobre a mesma, inspiradas sobretudo nas atitudes presentes nas operações (que se caracterizam como invasões truculentas), nas práticas de extorsão dos traficantes em troca do "arrego" 23 e no tratamento desumano e desrespeitoso que muitas vezes recebem por parte dos soldados e oficiais dessa corporação ${ }^{24}$. No trecho a seguir, Fábio deixa claro sua percepção

${ }^{23}$ Categoria que remete a prática de alguns policiais em liberar um possível detido, uma quantidade de drogas apreendidas ou a realização de um baile funk em troca do pagamento de uma quantia de dinheiro.

${ }^{24}$ Cunha aponta essa percepção negativa que os moradores das favelas têm dos policiais, assim como algumas das suas razões: "No caso da cidade do Rio de Janeiro, como exemplo dessa relação, podemos considerar a atuação policial, sobretudo nas favelas e bairros de periferia, geralmente caracterizada pelo autoritarismo e pelo desrespeito aos moradores. A percepção destes sobre a violência vivida em suas 'comunidades', embora vinculada de um 
da polícia, percepção essa partilhada entre muitos dos moradores das favelas e demais formas de periferias cariocas:

A gente sabe que a polícia, sabe até por amigos que são policiais, não acaba com o tráfico aqui na Cidade Alta porque não quer, porque são poucas saídas, eles conhecem muito bem o que é isso daqui e... não acabam com tudo. A gente sabe que hoje o tráfico aqui é extremamente enfraquecido, e não acabam porque não querem. Sabe que tem o baile funk aqui, eles vem de vez em quando. Há umas duas semanas atrás vieram, falaram que não ia ter baile funk, que é um inferno esse baile funk - e... mas conseguiram o arrego deles, o dinheiro deles, e foram embora. Então, assim, a gente é muito largado.

Parece que mais do que basear-se nas suas experiências, o perfil do policial que os moradores utilizam para avaliar a milícia e os milicianos se encaixaria dentro de um tipo ideal (no estilo weberiano) do policial como promotor da justiça e da paz e combatente da criminalidade, como aquele que luta pelo bem contra o mal, do potencial herói. É a filiação à imagem do policial ideal um dos elementos legitimadores da presença armada ostensiva dos milicianos. Não é à toa que alguns grupos de milicianos filiaram a sua imagem aos heróis dos quadrinhos (tipos ideais na luta contra o mal), como foi o caso da "Liga da justiça", um grupo da zona oeste da cidade que, além de fazer referência ao coletivo dos heróis da DC Comics, ainda usava o símbolo do morcego em uma oval (do justiceiro Batman ${ }^{25}$ ) como forma de caracterizar a sua presença.

modo ou de outro à questão do tráfico de drogas, encontra-se diretamente relacionada com a atuação da polícia [...]. Tal fato reforçaria ainda mais a percepção negativa da polícia por parte dos moradores de tais localidades". (CUNHA, 2004: 203-204).

${ }^{25}$ Interessante notar que o Batman, além de ser um herói, trabalha de forma colaborativa com a polícia de Gotham City, mesmo que clandestinamente. Esse mútuo-apoio clandestino entre milícia e polícia no Rio de Janeiro é sempre apontado, tanto pela imprensa como pelos especialistas no assunto. 
Competência/experiência versus amadorismo/inexperiência

Outro ponto que permite aos entrevistados perceber essa identificação com a polícia como um ponto positivo das milícias é apontado por Cano e Loot

\begin{abstract}
O fato de serem policiais lhes confere, em teoria, uma competência técnica para desempenhar funções de segurança, como acontece com os policiais que são contratados como agentes de segurança privada justamente em função da sua condição de agentes de segurança pública. Assim, quando os moradores estão pagando uma taxa, estariam com isso "contratando um profissional" (CANO; LOOT, 2008: 68).
\end{abstract}

Essa valorização de uma experiência e competência técnica do policial é ressaltada nas entrevistas. Sônia, quando procura mais uma vez desqualificar o grupo de milicianos com quem esbarrou na cidade Alta, traz a seguinte afirmação:

Ficamos aqui no corredor a noite todinha. Quando chegou de manhã, que meu marido foi trabalhar... ele foi trabalhar, e aí foi no ponto do ônibus, voltou, e falou: "Sônia, tá cheio de moleque novo aí, cheio de milícia. Cheio de miliciano".

Como já destaquei anteriormente, Sônia rejeita o grupo de milicianos por achar que o mesmo era formado por ex-bandidos. A percepção de seu marido de que os homens com quem cruzou eram "moleques novos" mais uma vez afasta esses milicianos da imagem da polícia, já que é o tráfico que recruta jovens pouco preparados para os seus grupos. A experiência, muitas vezes avaliada pela idade, é um elemento que caracteriza o bom policial, assim como em outros ramos profissionais.

Quanto à competência, é interessante o fato de que os entrevistados não atribuíram a retomada do tráfico à competência dos seus agentes, mas sim a algum infortúnio sofrido pelos milicianos (um acidente de percurso) ou o desinteresse dos mesmos pelo local após os dois dias de reconhecimento. Todos

Idéias - Rev. Inst. Filos. Ciênc. Hum. UNICAMP, v.6, n.2, p.195-224, jul/dez. 2015 
afirmam, direta ou indiretamente, acreditar que os milicianos seriam suficientemente capazes de permanecer atuando local, principalmente pela competência adquirida na experiência policial em lidar com os "bandidos". Nesse episódio, os traficantes são percebidos mais como sortudos do que vencedores:

\begin{abstract}
Não se sabe se eles foram embora por que quiseram ou por que expulsaram. Eu acho que foi por que quiseram. A impressão minha é que alguma coisa que eles esperavam daqui e que não era o que eles esperavam, entendeu? Não ia dar o lucro que eles pensavam. Por que eu não acredito muito nesse negócio de que os traficantes conseguiram expulsar eles não. Porque os bandidos daqui não são tão poderosos assim. E todos os lugares em que eles invadiram foram bem sucedidos, justo aqui eles iriam correr dos bandidos? Aí tem, né? (Zélia)

O que nos pareceu é que a milícia ficou muito tranquila, e naquela posse, por não ter sido nada muito difícil, não se armou como deveria para que a bandidagem retornasse a comunidade. E dentro disso, realmente, os milicianos que estavam na comunidade em guarda não foram suficientes para evitar que os próprios bandidos retomassem a comunidade. (Celma)
\end{abstract}

\title{
Conclusão
}

Segundo os entrevistados, no final da tarde do dia 04 de fevereiro de 2007, quando os milicianos já haviam sido "expulsos", os veículos da imprensa chegaram ao local para colher informações e noticiar o ocorrido. Sônia e Gilmar relataram um episódio curioso: Segundo estes, alguns traficantes e pessoas próximas a eles entravam nos prédios e convocavam os moradores a se manifestarem contra a milícia para os jornalistas. $\mathrm{O}$ pedido não vinha acompanhado de uma imposição pela força ou autoridade, 
tanto que muitos moradores como Sônia e Gilmar, se recusaram a descer de seus apartamentos e não sofreram represália por isso.

Fazendo uma interpretação bem livre do fato, me aventuro a dizer que tal pedido não era imposto, mas solicitado pelos traficantes em nome de uma história longa construída em conjunto, como se os mesmos, apesar da relação instrumental conservada com os moradores desse espaço, invocassem elementos positivos da sua atuação no local, como a proteção oferecida por anos a fio sem cobrar qualquer taxa por isso. Foi a opção palpável e sempre presente nesse contexto de políticas públicas de segurança que nunca atenderam aos anseios da população local.

Pedir a denúncia dos milicianos significa reconhecer uma troca dos papéis, algo certamente possível em outro conjunto de valores: o traficante se percebe, e também é percebido por alguns, como o ordenador, o justiceiro, o protetor, o experiente, o capaz afinal, quem venceu a guerra? Quem manteve a localidade "segura" por tantos anos? - diferente do miliciano, que é o explorador, o estrangeiro, o fracassado, aquele que se aproveita da máquina pública para agir criminosamente. No final desse episódio, mais do que se manter pela força, os "bandidos" precisavam legitimar a sua presença, assumir o papel do bem, daquele que conseguiu heroicamente "espantar os verdadeiros vilões". Esse episódio mostra como a disputa pelos significados de violência, justiça, legalidade e competência se manifestam de forma bem mais complexa no contexto dinâmico da violência urbana carioca.

\section{Referências}

ALVES, José Claúdio Souza. "Milícias: Mudanças na economia política do crime no Rio de Janeiro". In JUSTIÇA GLOBAL. Segurança, tráfico e milícias no Rio de Janeiro. Rio de Janeiro: Fundação Heinrich Böll, 2008.

CANO, Ignacio; LOOT, Carolina. "Seis por meia dúzia?: Um estudo exploratório do fenômeno das chamadas 'milícias' no Rio de 
Janeiro". In JUSTIÇA GLOBAL. Segurança, tráfico e milícias no Rio de Janeiro. Rio de Janeiro: Fundação Heinrich Böll, 2008.

CONCEIÇÃO, Wellington da Silva. Mobilidade e fixação: A trajetória social dos moradores do Conjunto Habitacional Cidade Alta - RJ. 74 f. Monografia (Bacharelado em Ciências Sociais) - Instituto de Humanidade - Universidade Candido Mendes, Rio de Janeiro. 2008.

CUNHA, Neiva Vieira da. "Como se fabrica um policial: considerações em torno dos processos de socialização e formação profissional". In: Comum, v. 9, n. 22, 2004, p. 198207.

LEEDS, Elizabeth. "Cocaína e poderes paralelos na periferia urbana brasileira". In ZALUAR, Alba \& ALVITO, Marcos. Um século de favela. Rio de Janeiro: FGV, 2004.

LEITE, Márcia Pereira. “Entre o individualismo e a solidariedade: Dilemas da política e da cidadania no Rio de Janeiro". In Revista Brasileira de Ciências Sociais, Vol. 15, n. 44, 2000, p. 73-90.

. "Violência, risco e sociabilidade nas margens da cidade: Percepções e formas de ação de moradores de favelas cariocas". In MACHADO DA SILVA, Luiz Antonio (org.). Vida sob cerco: Violência e rotina nas favelas do Rio de Janeiro. Rio de Janeiro: Nova Fronteira, 2008.

MACHADO DA SILVA, Luiz Antonio. “Sociabilidade violenta: Por uma interpretação da criminalidade contemporânea no Brasil urbano". In Sociedade e Estado, v. 19, n. 1, 2004, p. 53-84.

. "Violência urbana, sociabilidade violenta e agenda pública". In (org.). Vida sob cerco: Violência e rotina nas favelas do Rio de Janeiro. Rio de Janeiro: Nova Fronteira, 2008.

MISSE, Michel. "Mercados ilegais, redes de proteção e organização local do crime no Rio de Janeiro". In Estudos Avançados, n. 21 (61), 2007, p. 139-157. 
. "Sobre a acumulação social da violência no Rio de Janeiro". In Civitas, v.8, n.3, 2008, p. 371-385.

NASCIMENTO, Denise Nonato do. Favela de cimento armado: Um estudo de caso sobre a organização comunitária de um conjunto habitacional. 133 f. Dissertação (mestrado em Ciências Sociais) - Universidade do Estado do Rio de Janeiro, Rio de Janeiro. 2003.

ROCHA, Lia de Mattos \& SILVA, Itamar. "Associações de moradores de favelas e seus dirigentes: $O$ discurso e a ação como reversos do medo". In JUSTIÇA GLOBAL. Segurança, tráfico e milícias no Rio de Janeiro. Rio de Janeiro: Fundação Heinrich Böll, 2008.

TELLES, Vera da Silva. Nas dobras do legal e do ilegal: Ilegalismos e jogos de poder nas tramas da cidade. In: Dilemas. Vol. 2, n. 5-6, 2010, pp. 97-126

ZALUAR, Alba. A máquina e a revolta: As organizações populares e o significado da pobreza. São Paulo: Brasiliense, 2000.

Matérias de jornal impresso:

SILVA, Letícia Vieira. Cordovil: tráfico toma de volta morro que milícia ocupou. O Globo, 05/02/2007.

\section{Matérias de internet:}

TERRA. Milícia recruta homens para novo ataque no Rio. Texto disponível em: http://noticias.terra.com.br/brasil/ noticias/0,,OI1397975-El316,00-milicia+recruta+homens+para+novo +ataque+no+Rio.html. Texto de Fevereiro de 2007. Acesso em 21/07/2011.

TERRA. PM busca bandidos em favelas após sete mortes. Texto disponível em: http://media.terra.com.br/imprime/0,,Ol1390421El316,00.html. Texto de Fevereiro de 2007. Acesso em $21 / 07 / 2011$. 